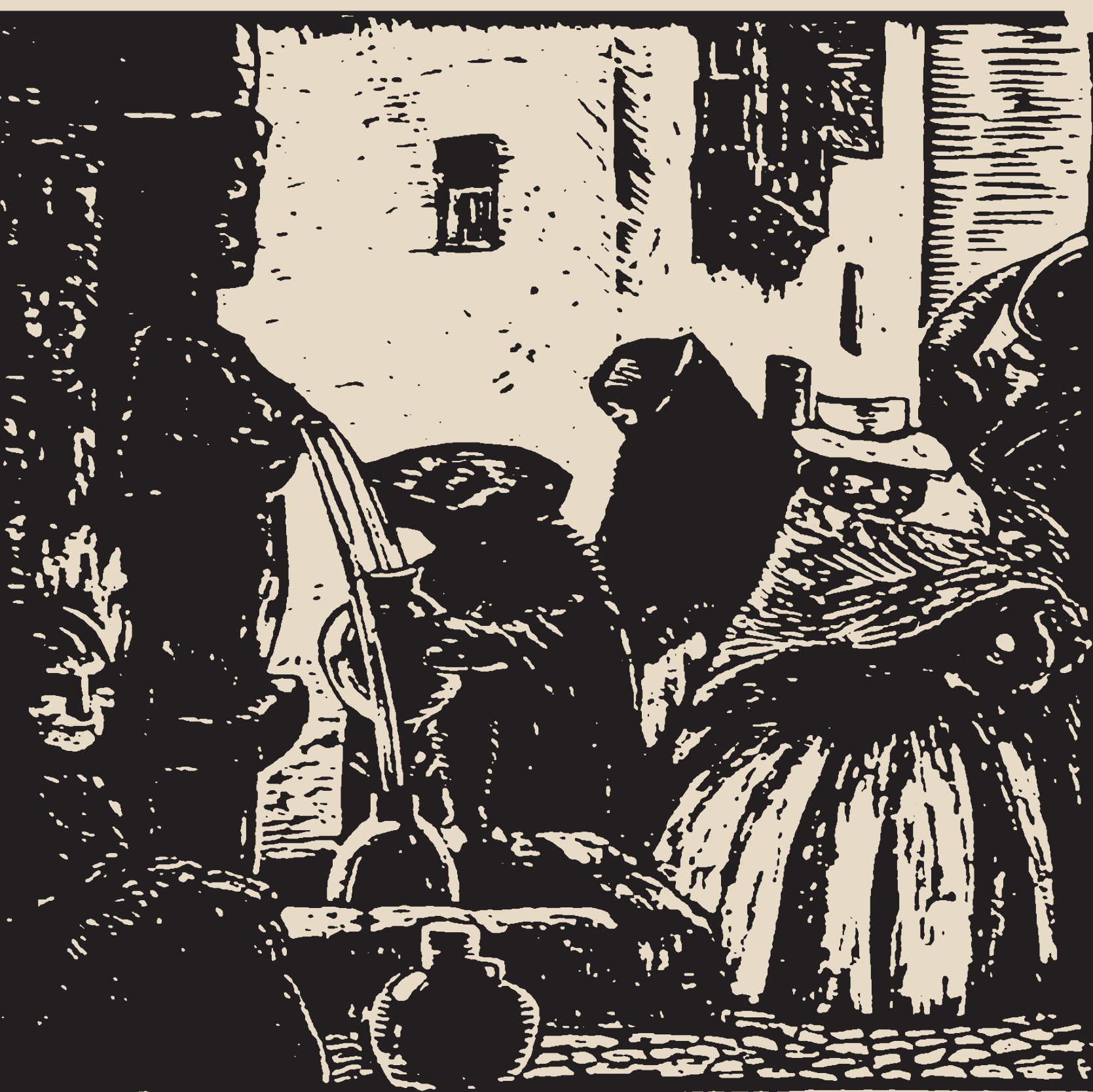

Fuente de Arones. José Sabogal, grabado. 1925. Esta "Mama" buena verdinegra y brillante adosada al muro ofreciendo eternamente sus senos a los sedientos y coronada por el Sol. 


\title{
Temperamento y estética de dos notables pintores. Cartas de José Sabogal a Manuel Domingo Pantigoso
}

Manuel Pantigoso Pecero

Oficina Central de Extensión Cultural y Proyección Social / Universidad Ricardo Palma panti@terra.com.pe

\begin{abstract}
Resumen
El artículo sitúa al Cuzco como tierra inspiradora y raigal en la visión indigenista de José Sabogal y en la visión ultraorbicista de Manuel Domingo Pantigoso. Se remarca la inicial amistad entre dos pintores de coincidencias existenciales pero con diferentes propuestas estéticas. Luego se transcriben y se analizan detalladamente tres cartas dirigidas por Sabogal a Pantigoso: la primera dedicada especialmente a "Cunan", revista de la Vanguardia del Sur; la segunda referida a la Escuela de Bellas Artes; y la tercera a la exposición en Arequipa de artistas residentes en Lima, presentada por Pantigoso en el "Arequepay". Se finaliza con las conclusiones que surgen de las posturas temperamentales de cada uno (vertical la del cajamarquino y horizontal la del arequipeño) y de la forma de entender el color en la realización plástica.
\end{abstract}

Palabras clave: Cuzco, ultraorbicismo, indio, crisis social, temperamento, originalidad

\begin{abstract}
The article places Cuzco as an inspiring land and the cradle of the indigenous vision of Jose Sabogal and the ultraorbicist vision of Manuel Domingo Pantigoso. It emphasizes the initial friendship between two artists with existential coincidences but with different aesthetic proposals. Then, three letters addressed by Sabogal to Pantigoso are transcribed and analyzed in detail: the first one dedicated especially to "Cunan", a magazine of the Vanguard of the South; The second refers to the School of Fine Arts; And the third to the exhibition in Arequipa of artists residing in Lima, presented by Pantigoso in the "Arequepay". This article ends with the conclusions that arise from the temperamental postures of each one of them (vertical from the "Cajamarquino" and horizontal from the "Arequipeño") and the way of understanding the color in this fine art development.
\end{abstract}

Keywords: Cuzco, ultraorbicism, indigenous, social crisis, nature, originality

\section{El contexto}

Manuel Domingo Pantigoso (Arequipa, 1901-Lima, 1991) y José Sabogal (Cajamarca, 1888Lima, 1956) iniciaron una cordial amistad a partir de 1925, en el Cuzco, ciudad que marcaría la ruta de sus propuestas estéticas. La identificación de Pantigoso con la Ciudad Imperial -la tierra de su padre-fue proverbial, tanto que ciertos críticos peruanos y extranjeros lo consideraban pintor cuzqueño, sin que él los desmintiese -y hasta los alentase en 
algunos casos- porque se enorgullecía de sus raíces y porque así se afirmaba mejor como pintor del sur del país. Sabogal, por su parte, luego de permanecer en suelo argentino, desde 1910 hasta noviembre de 1918, ingresó al Perú por el lago Titicaca y radicó algunos meses en tierra cuzqueña, ahondando su visión raigal del indio. Al año siguiente (1919) el artista cajamarquino, trece años mayor que su colega, expuso en Lima, en la Casa Musical Brandes $^{1}$ (ubicada en la calle Espaderos 529). José Torres Bohl apunta que "Sabogal había realizado en el Cuzco, entre el 20 de noviembre de 1918 y el 20 de mayo de 1919, las telas que exhibió en la Casa Brandes, a excepción de Carnaval de Tilcara, cuadro pintado en Jujuy, Argentina" (1989:20). Poco después, en 1922, se casaría con la escritora María Wiesse. Luego del retorno de Mariátegui de Europa estaría muy vinculado a su cenáculo que funcionaba en la casa de Washington Izquierda.

El año 1925 Manuel Domingo Pantigoso expuso, con Armando Lazarte y Camilo Blas, en el salón de San Bernardo, en $\mathrm{Cuzco}^{2}$. Con el segundo, incluso, compartirá su taller de pintura en el barrio de Huaynapata. Antes del viaje a Lima del pintor cajamarquino, como muestra de amistad y confidencia le diría a Pantigoso refiriéndose con cariño a su paisano: "se lo recomiendo a Camilo; logre usted que ponga más fuerza en sus cuadros” (Pantigoso, 1996: 20). Con los años muchos interesados pretendieron ampliar las naturales diferencias entre ellos, fomentando así una inexistente enemistad. Las propuestas de ambos fueron diferentes, eso sí era cierto pues distintas estéticas los separaban: indigenismo e indianismo ultraórbico. Pero por encima de ello, ninguno faltó a la amistad y al respeto que se debían. Recordando los primeros meses de los años 26 y 27, antes de viajar finalmente a Europa (1927-1930), Pantigoso diría en 1985: "Solía visitarlo dos veces por semana en la Escuela de Bellas Artes. Todos los artistas de la época eran muy amigos: Sabogal, Julia Codesido, Ricardo Grau"3.

Fernando Villegas Torres, en su excelente libro Vínculos artísticos entre España y el Perú (18921929), hace un paralelo entre Pantigoso y Sabogal a partir de sus divergencias y sus aproximaciones, y de la propuesta vanguardista en el empleo de la xilografía. Apunta que: "no existió entre ellos un antagonismo radical, sino que coexistieron, e incluso compartieron sala y estudio" (2016:218). La comprobación de que había, por lo menos en los primeros años, una amistad sincera la podemos comprobar a través de la comunicación epistolar. Contamos para ello con tres cartas de Sabogal dirigidas a Pantigoso, fechadas en 1931, 1932 y 1933 . Fueron épocas cruciales y complicadas en la historia del Perú. Por eso, los años del 30-36 son conocidos con el nombre de "Generación de la Crisis".

Nuestro artículo tiene como objetivo analizar textualmente dichas misivas, hurgando en sus líneas y entrelíneas, en el contexto social y artístico de la época, en cómo era la confianza de Sabogal por Pantigoso, en los aspectos temperamentales de ambos.

1 Ese mismo año (1919), Pantigoso efectuará, dos años después de su colectiva de 1917, la primera individual en el estudio fotográfico de Max T. Vargas, en Arequipa. Tenía entonces solo 18 años.

2 Se refiere a un hermoso salón de construcción colonial, propicio para efectuar exposiciones de importancia.

3 Entrevista concedida al diario “El Comercio”, el sábado 13 de abril de 1985. 


\section{Las tres cartas de Sabogal ${ }^{4}$}

1 .

Lima, 14 de mayo de 1931

Estimado Pantigoso:

Recibí el 3 de "Cunan", pero no me encontró el amigo Carreño que Ud. me recomienda y que tendré mucho gusto de conocer y de servir.

El esfuerzo de Uds. es bien loable, pero no así el esfuerzo de los tipógrafos é impresores. Es necesario que Uds. vigilen y hagan la "armadura", buscando de variar el tipo que es bien vulgar. Pero sobre todo la impresión de este último número es sumamente descuidada. Le vuelvo a decir que esa revista podrá adquirir fuerte vida con la colaboración de todos y muy en especial con la presentación.

En próxima carta le enviaré en estampillas el valor de todos los números que he recibido, pero en adelante mándeme para mí solo diez ejemplares como suscritor.

Como Ud. se habrá enterado otra vez nos encontramos en danza y conforme van sucediéndose los acontecimientos acabaremos en una "Kashua" de esas bien trágicas.

Me explico que Uds. no puedan evadirse de algunos "grabadores" que Ud. sabe quien es pero traten de no dar cabida en bien del prestigio de la revista. Este joven Olazo tiene la sugestión de París. Nunca ha sido cuna de arte París. Podrá ser centro del arte moderno mundial pero sí es cuna el arte sudamericano, el Cuzco, Chan Chan, Nazca, etc. No hay por qué salirse del medio en la revista americana.

Saludos a los muchachos y Ud. uno especial de su amigo

J. Sabogal

2.

Lima 27 de noviembre de 1932

Estimado amigo Pantigoso:

Recibí “Cunan", trae un interesante artículo de Camilo.

Toia no me encontró ni yo lo he encontrado en el hotel. Pero ya nos veremos y cumpliré con Ud. y puede que cunda una amistad genuina.

Lo de la Dirección de la Escuela de Bellas Artes, promete ser un asunto apasionante para el año que viene. Desde el finado Hernández hasta el civilista Barreda me propusieron al gobierno. Y unas doscientas firmas de ex alumnos-artistas y el alumnado en totalidad elevaron la solicitud hace ya un mes.

Yo me resisto y he manifestado a la Comisión de estudiantes que solo aceptaría la Dirección en el amplio concepto que tiene esta palabra, quiero decir que no hayan trabas ni compromisos de puesto por ningún lado, ni del gobierno ni del alumnado. Y que solo me haría cargo con la finalidad de acometer una intensa labor pictórica que beneficie a todo el país en forma de misiones rotativas. Mi primera etapa sería sentar la Sede del Sur en Arequipa para bifurcarla a Puno y Cuzco.

4 No sabemos si hubo otras cartas. Las que están en nuestro poder fueron encontradas en los archivos de Manuel Domingo Pantigoso, días después de su muerte. 
Yo no admito se siga lo que hasta hoy se ha seguido. Pero el gobierno hasta hoy nada resuelve y extraoficialmente sé que seré nombrado interino. Solución que nada resuelve y que permite mayor intriga a elementos pintorescos como Natalicio, fotógrafos de aquí y también aventureros. Yo veo en esto una lucha de derechas é izquierdas -es decir-política, sin tener en cuenta que los artistas son únicamente artistas.

Yo le adjunto para la Agrupación Hogar del Artista - "Arequepay" una hoja de mi agradecimiento y mi felicitación por su interpretación.

Gracias por sus saludos

Reciba un abrazo

Sabogal

3.

Lima 26 de marzo de 1933

Estimado amigo Pantigoso:

Recibí la suya del 18 con el catálogo y los recortes. Ud. ha hecho la exhibición calientita antes de que se enfríe. Muy bien, solo que esa "artista Ritter", nadie le ha visto nada aquí y solo en Arequipa resulta artista "capitalina".

Me ha dado Ud. una sorpresa con los óleos que le ha prestado 5 a Mr. Róden. No está mal que se aireen un poco y aprovecho de esta oportunidad para que me haga tomar unas fotografías cuadro por cuadro -13×18- con el impagable Mansilla a quien me hará Ud. el favor de saludarlo. Naturalmente que creo es necesario hacer las fotografías con la venia del Sr. Róden. 3 copias de cada uno ampliadas en $18 \times 24$ y las planchas que Ud. me las enviará por correo, diciéndome el costo para enviarle ó cobrarse del valor de algunas maderas que espero adquieran los arequipeños en esta ocasión.

Los recortes deliciosos así como las palabras pronunciadas. Detrás de todo eso hay sincero deseo de cultura.

El número de Cunan saldrá pero yo creo que demora algo. Ud. sabe que aquí estamos fatalmente coludidos a ciertas circunstancias que traban la libre expresión aunque sea plástica. Pero saldrá.

Codesido, Flores, Camilo. Todos se han enterado de los recortes que Ud. me ha enviado y me encargan retorne sus saludos.

De mi parte especiales saludos a los amigos y Ud.

Un abrazo de su amigo

J. Sabogal

5 Debe haber un error en el verbo utilizado: "prestado" por pedido, también la frase tendría sentido si quizo decir "que le ha prestado". Mr. Roden. 
Temperamento y estética de dos notables pintores. Cartas de José Sabogal a Manuel Domingo Pantigoso

65

Iot recortes deliciosos an' comolos patares pronuciadas. Dunsis de toos eso bay sincers deseo de entura.

SI mimen de Cunan Sordin pess yo oreo que demorá algo. Yd. Solve que aqni estamas futalmenty colindidios à ciertad cirens tancias que traban ta libre expresion aunque toa plistica. Peso sarrá

Coderiar-Florez-Canilo- Todos se han entersods de los recortes que bd. sue ha emnabo encergan retopre sus salubos. De ni parte expecials sulues a fos anifos of bd. Un abraso de su amifo

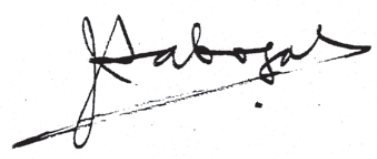

Fig.1. Fragmentos de la tercera carta de José Sabogal (Lima, 26 de marzo de 1933) a Manuel Domingo Pantigoso.

Mana Tukukuq ILLAPA 2016, 13 (13): 60-71

Revista del Instituto de Investigaciones Museológicas y Artísticas de la Universidad Ricardo Palma 


\section{La interpretación textual}

\section{Primera carta}

La primera misiva hace referencia al tercer número de Cunan, revista que apareció en 1931 y se proyectó hasta el siguiente año de 1932. Cuatro salieron en el Cuzco, una -doble- en Puno y otra en Arequipa ${ }^{6}$. Su principal impulsor fue Manuel Domingo Pantigoso, quien invitó a otros pintores para que compartiesen con él la dirección, entre ellos: Víctor Martínez Málaga, Francisco Olazo, Domingo Velasco Astete, Carlos Trujillo y Federico Molina.

Desde el inicio de la carta hasta el final se percibe el especial afecto que en ese momento tiene Sabogal por su colega: lo llama "Estimado Pantigoso". Además, hay la confianza suficiente como para que el plástico arequipeño le recomiende a un amigo de apellido Carreño, que podría ser un joven pintor buscando algún favor del maestro.

Sobre la diagramación de Cunan, Sabogal pone reparos en el aspecto visual y tipográfico, poco convincente a su entender. Sin embargo, es amable para expresar su opinión sin herir a sus colegas: "El esfuerzo de Uds. es bien loable -dice-, pero no así el esfuerzo de los tipógrafos é impresores”. En sus palabras está el artista experimentado que emite opiniones con firmeza profesoral pero sin la necesaria comprensión como para entender que no se puede juzgar a las revistas de provincia con los mismos criterios con los que se juzgan a las revistas limeñas, especialmente a "Amauta" con la cual estuvo profundamente relacionado desde el primer número. Las expresiones de Sabogal para Cunan son muy significativas: "La tipografía es bien vulgar", "Es necesario que ustedes vigilen y hagan la "armadura”, "le vuelvo a decir...", "traten de no dar cabida en bien de la revista".

Generalmente las revistas de la época eran artesanales; tenían deficiencias que saltaban a la vista: precariedad en la compaginación, en la corrección de estilo, en los signos tipográficos, tal como se observa en otras revistas del sur como Kosko dirigida por Roberto Latorre, Alma Quechua conducida por Humberto Pacheco, Puno Lírico con la dirección de Enrique Ancieta, etc.

Pero Sabogal se muestra solidario con los directores de la revista y pide diez ejemplares como suscriptor.

El pintor de Cajamarca alude también a la problemática social que se vivía entonces. Lúcido es en la predicción pues al año siguiente (9 de enero de 1932) se promulgó una "Ley de Emergencia" que a la larga desaforó y desterró a veintitrés parlamentarios apristas. Todos estos hechos provocarían el atentado contra la vida del presidente, el 6 de marzo, que lo pondría al borde de la muerte. Luego estallaría un motín en la armada, el 8 de mayo del mismo año. Con este y otros pretextos, la Universidad Nacional Mayor de San Marcos fue recesada. Y acentuando el malestar generalizado, el 7 de julio oficiales del ejército serán masacrados en el cuartel de Trujillo, con motivo de la revolución aprista que se extendió a Huaraz, Cajamarca y Huancavelica dejando numerosas víctimas en ambos bandos.

En otro párrafo Sabogal hace velada alusión a "algunos grabadores” que según él no tienen el mérito suficiente para ilustrar las páginas de la revista. Aquí está nuevamente su postura intransigente, diferente a la visión tolerante de Pantigoso para quien todos tenían el derecho de mostrar sus posibilidades artísticas. Y en Cunan hay profusión de grabadores, muchos de gran calidad.

En este tercer número de Cunan está la presencia de Sabogal a través de dos grabados: "La Fuente de Arones” y “Tinterillo". Participa, además, escribiendo un artículo sobre esa

6 Recordemos que antes de Cunan revistas emblemáticas como el Boletín Titicaca, Amauta, Variedades, Mundial y La Sierra llegaron a su fin como consecuencia de los nefastos sucesos surgidos en 1930 con la ascensión al poder de Luis Sánchez Cerro, quien inició una revolución en Arequipa para deponer al presidente Leguía. 
emblemática fuente en donde da cuenta a la colectividad cuzqueña sobre la barbarie que significa haber arrancado de su lugar de origen al entrañable vertedor de agua de gran valor simbólico para la ciudad:

Esta "Mama" buena verdinegra y brillante adosada al muro ofreciendo eternamente sus senos a los sedientos y coronada por el Sol era la realización plástica más popular del pueblo cusqueño. (...) En la noche chapoteaba cantarina el agua vertida de los robustos senos de la mujer de piedra. Los sedientos acercaban sus labios al pezón y la figura plástica sorprendida, tierna y fuerte, quedaba grabada en el recuerdo para siempre. (...) La "Mariangola" debió tocar a rebato el día que se cometió el atentado. Esta campana famosa y la humilde fuente de "Arones" son "huacas" que tienen el mismo profundo valor popular (Sabogal, marzo 1931, parr 2).

Escrito en bella prosa, el texto demuestra el pulso literario de Sabogal aplicado a testimoniar la defensa de la tradición que la revista alentaba. Por eso, el texto fue publicado en la primera página a modo de manifiesto.

Sabogal es tajante al refutar el artículo de Francisco Olazo titulado "La vida artística en otros mundos. París cuna del arte". Para él, como para Pantigoso y los pintores de Cunan, el arte sudamericano era una proyección del legado de las grandes culturas aborígenes. Ellos hacen, pues, una causa común sobre este tema. Lo dicho por el abanderado del Indigenismo tiene la impronta de una profesión de fe para los pintores del Indianismo ultraórbico, como se aprecia en la declaración grupal titulada "Nuestros Principios" (Cunan, 1931). Aquí se marca distancias frente a la postura de Olazo quien, por lo visto, no concordada con la línea y la doctrina de la revista. El disidente es visto, sin ser nombrado, como vanidoso, con desmedi-
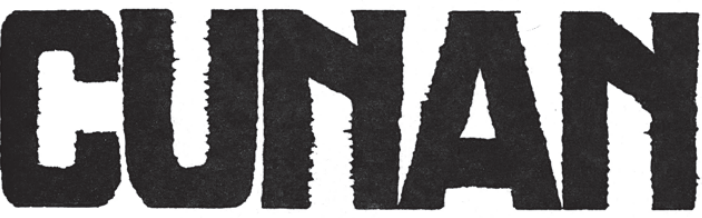

Labor de los artistas suramericanos Encargadoe de la Direcció 3

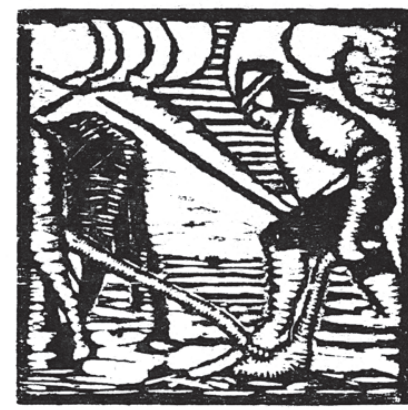

cuzco

1931

Fig.2. Carátula de la Revista CUNAN N³ (aparece un texto de José Sabogal de denuncia sobre LA FUENTE DE ARONES: el retiro de la fuente colonial de Arones de su emplazamiento tradicional del Cuzco antiguo) y TINTERILLO (Huanta: Madera). do orgullo ${ }^{7}$.

\section{Segunda carta}

Fechada el 27 de noviembre de 1932 la carta contiene datos muy interesantes. Sabogal acusa recibo de Cunan 6 y demuestra desde el inicio que desea hablarle a Pantigoso de la Escuela de Bellas Artes. Pero inicia sus palabras refiriéndose al artículo de Camilo Blas que apoya totalmente, escrito en tono beligerante pero certero, titulado "Nuestra seudocrítica

7 Para este número Olazo es reemplazado, en la dirección conjunta, por Domingo Velasco Astete. 
de Arte". Aquí el autor arremete contra ese diletantismo y esa improvisación que imperaba en la crítica pictórica de entonces, afectada por el sometimiento visual y conceptual respecto a las formas importadas de Europa. El escrito es importante porque pertenece a uno de los más connotados discípulos de Sabogal que, como él, era cajamarquino. Blas (que había estudiado en la Escuela Nacional de Bellas Artes de Lima bajo la dirección de Daniel Hernández y luego con el propio Sabogal, reafirma ese antiacademicismo que los comprometidos con Cunan asumieron como una oriflama. Luego de esta alta calificación otorgada al trabajo de Camilo Blas, Sabogal dice que no se ha comunicado con Toia (¿?), que bien podría ser el "Carreño" de la primera carta.

La misiva ha de referirse, de manera central, a los pormenores del vacío creado en la Escuela de Bellas Artes luego de la muerte de Daniel Hernández. Sabogal cuenta la propuesta que tiene para ejercer la dirección de la ENBA. Califica a las personas con intencionada ironía: "Finado Hernández", "Civilista Barreda”. Este último es el pintor Enrique Domingo Barreda quien en 1920 tuvo participación activa en el hecho de lograr que el pintor indigenista formara parte del cuerpo docente de la EMBA. Lo que sigue de la carta parece un documento psicológico del firmante. Primero manifiesta, con firmeza y orgullo, el abrumador pedido de "exalumnos-artistas" y del "alumnado en totalidad" para que él tome la posta dejada por Hernández; expresa, entonces, sentimientos directos y tajantes: "yo no admito", "yo me resisto", y pone, al mismo tiempo, condiciones para su participación, siempre y cuando "no hayan trabas ni compromisos de puesto por ningún lado, ni del gobierno ni del alumnado”. Luego le informa a su amigo que su aspiración es "acometer una intensa labor pictórica que beneficie a todo el país en forma de misiones rotativas", buscando sentar la sede del Sur en Arequipa. Supuestamente desea ser un abanderado y realizar el mismo itinerario geográfico seguido por Cunan. Casi en voz baja, como una confidencia, le dice: "el gobierno hasta hoy nada resuelve y extraoficialmente sé que seré nombrado interino". Y al lado de estos comentarios hay en esta segunda carta una confesión de fe y un gesto de afirmación que nos parecen muy valiosos: "Yo veo en esto una lucha de derechas e izquierdas -es decir- política, sin tener en cuenta que los artistas son únicamente artistas". Esta postura fue también la de Pantigoso.

Para finalizar, Sabogal menciona al "Arequepay, Hogar del artista”, creado por Pantigoso en la Ciudad Blanca, agradeciéndole a la institución el apoyo recibido para abrir sus puertas a la exposición colectiva. Este dato que ofrece la carta es otra demostración de esa amistad y esa confianza que entonces existía entre los dos pintores.

\section{Tercera carta}

En la tercera carta, fechada el 26 de marzo de 1933, el ya director de la Escuela de Bellas Artes desde el año anterior reitera su impresión sobre la exposición realizada en el "Arequepay" de la Ciudad Blanca con cuadros de grandes artistas radicados en la capital, bajo la conducción de Manuel Domingo Pantigoso. A solicitud de este, varios óleos de Sabogal fueron prestados para la muestra por "Mr. Roden”, dueño de los cuadros. En la carta Sabogal está feliz y admirado por la solvencia organizativa de Pantigoso, pero su amigo es extremadamente severo y displicente contra "esa artista 'Ritter' (que) nadie le ha visto nada aquí y solo en Arequipa resulta artista "capitalina”. Sin embargo, se trata de Rosa Ritter, alumna de la Escuela de Bellas Artes y excelente miniaturista ${ }^{8}$. Su presencia en dicha colectiva estuvo sustentada en el distinto juicio artístico de Pantigoso: en aquella actitud abierta y amable, no discriminadora, que años después, en 1937, lo llevaría a organizar el

8 La exposición constó de lo siguiente: siete óleos y trece grabados en madera de José Sabogal; ocho grabados en madera de Julia Codesido; diez óleos y dos carbones de Ricardo Flores; dos óleos, nueve grabados en madera, tres aguatintas y tres carbones de Camilo Blas; una miniatura al carbón de Rosa Ritter; un carbón del escultor Ismael Pozo. 
Primer Salón de los Independientes. En una carta de Rosa Ritter, que poseemos, fechada en Barranco, el 24 de marzo de 1933, es decir, dos días antes de la tercera carta de Sabogal que estamos analizando, esta artista le revela a su amigo arequipeño lo que piensa y siente de la Escuela de Bellas Artes:

Agradecemos la amable acogida que he tenido tanto en el Hogar como en el público arequipeño, todo ello debido en gran parte a su generosa y espontánea galantería, en mostrar mi trabajo y calificarlo en términos muy halagadores para mí.

Ante todo le hago presente, y haga constarlo, que la Escuela de Bellas Artes no me ha formado, lo siento al decirlo pero allí no he encontrado ni siquiera quien me enseñase a tomar el lápiz, solo conservo recuerdos muy ingratos de ese centro de enseñanza; francamente si no hubiera sido por mi carácter luchador y vehemente, tal vez los escasos meses que estuve allí habrían bastado para hacerme odioso el arte y abandonarlo definitivamente.

Con ese espíritu de sumar para crecer sin aquellos protagonismos que marginan, Pantigoso le había solicitado a Sabogal que el séptimo número de Cunan saliese bajo su conducción en Lima, donde residía. Puntualmente le cedía la dirección de la revista pues anhelaba que Cunan, que también circulaba ya en Bolivia, diese el salto a la capital. Pero sus esperanzas chocarían con la dura realidad que vivía el país. A pesar de la buena disposición de Sabogal ("saldrá pero yo creo que demora algo (...) pero saldrá”), Cunan nunca más volvió a aparecer. También cabe la posibilidad de que Sabogal no quiso comprometerse y encontró una buena disculpa. Lo cierto es que esa etapa de penumbra nacional no asolaría solo el espacio político y social, sino también, el plástico y literario del país.

\section{Conclusiones}

Las cartas de modo general evidencian el temperamento vigoroso, a ratos vertical e intransigente del gran orientador del Indigenismo. También demuestra la cercana amistad con quien era el abanderado del Ultraorbicismo pictórico (Indigenismo de Vanguardia, surgido desde Puno), más abierto y democrático en su línea de pensamiento. Eran, sin duda, de temperamentos diferentes, y aunque estéticamente tenían también diferencias que el tiempo las fue acentuando, nunca se resquebrajaría esa aproximación amical y de respeto que había entre ellos, incluso en los más álgidos momentos cuando el Indigenismo y la Escuela de Bellas Artes, motivados por cierta impronta socializante, tuvo múltiples detractores. Mercedes Gallagher de Parks criticaba esa inclinación que existía entonces: "Hacer arte doctrinario -decía- es simple y llanamente matar el germen creador" 9 . A

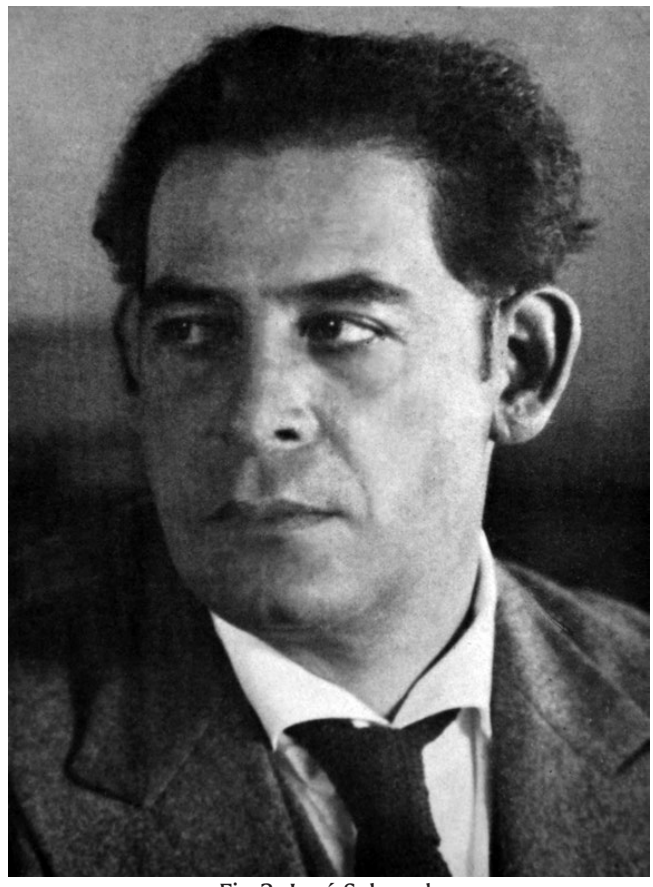

Fig.3. José Sabogal.

9 Carta del 4/4/1939 dirigida a Enrique Domingo Barreda, publicada en el diario La Prensa de Lima, el 16 de abril de 1939. 


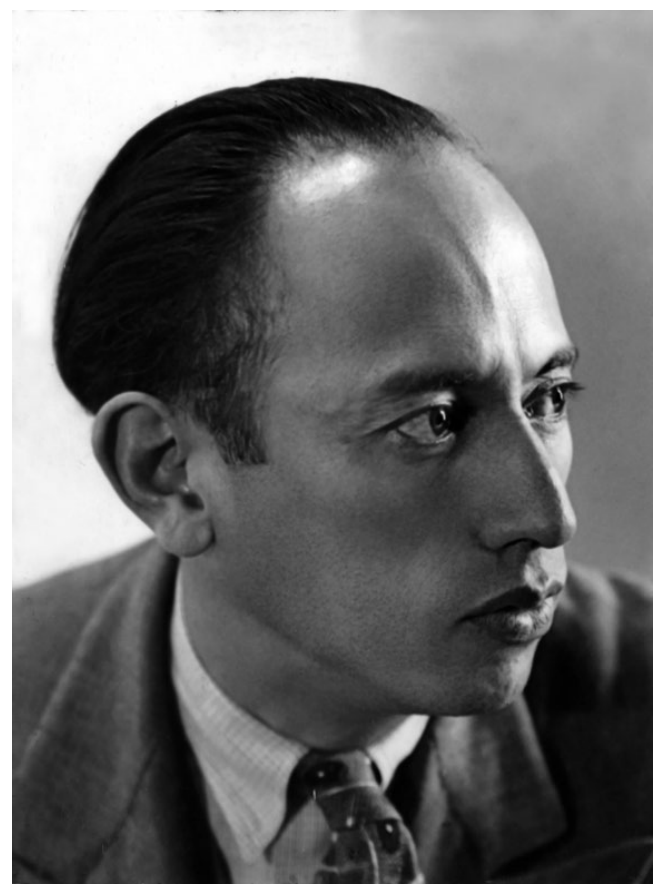

Fig.4. Manuel Domingo Pantigoso.

pesar de esas distancias pictóricas -y quizás por eso mismo- Pantigoso invitaría a Sabogal a la primera y exitosa muestra de los Independientes, de 1937, pero este declinó aduciendo que inauguraría una exposición individual en los Salones de la Sociedad Filarmónica de Lima. Era indudable que la amistad ya no era la misma. El tiempo y las circunstancias de estar frente a dos posiciones distintas habían contribuido para ello ${ }^{10}$.

Las distancias o diferencias entre las propuestas de Pantigoso y Sabogal se fueron decantando especialmente durante los años 35-50 por gran parte de la crítica pictórica de entonces $\mathrm{y}$, también, por los dos bandos que los cercaban con distintas intenciones. Hubo, inclusive, insinuaciones y pedidos para que Pantigoso reemplazase a Sabogal en la dirección de la Escuela de Bellas Artes, lo cual, obviamente, fue rechazado por el artista del sur del Perú.

Poco a poco, los caminos que abrieron ambos maestros fueron encontrando su verdadero destino. Alberto Tauro del Pino diría al respecto en una conferencia de 1991 ofrecida con motivo del fallecimiento del pintor arequipeño, acaecido 35 años después de la desaparición del artista cajamarquino: "Pantigoso y Sabogal son diferentes pero ambos descubren el alma y la raíz del Perú para definir su personalidad”.

\section{Referencias}

Fernández, J. (1995). Grabadores en el Perú (1st ed.). Lima: Didí de Arteta.

Lauer, M. (2007). Introducción a la pintura peruana del siglo $X X$. Lima: Universitaria de la Universidad Ricardo Palma.

Pantigoso, M. (1996). Manuel Domingo Pantigoso, mi padre. Lima: Harold's Graphics.

Pantigoso, M. (2007). Pantigoso. Fundador de los independientes. Lima: Ikono.

Pantigoso, M. (2014). La revista "Cunan" y el pintor Pantigoso (1931-1932). Lima: Tarea Asociación Gráfica Educativa.

Revista Cunan. Edición facsimilar (2014). Universidad Ricardo Palma. Editorial Universitaria. Lima 33, Perú.
Sabogal, J. (2014). La fuente de Arones, en Cunan 1931. Edición facsimilar. Universidad Ricardo Palma. Editorial Universitaria. Lima 33, Perú.

Tauro, A. (1987). Enciclopedia Ilustrada del Perú. Lima: Peisa.

Torres Bohl, J. (1989). Apuntes sobre José Sabogal. Vida y obra. Lima: Fondo Editorial del Banco Central de Reserva del Perú.

Villegas Torres, F. (2016). Vínculos artísticos entre España y el Perú (1892-1929). Lima: Fondo Editorial del Congreso del Perú.

10 Por los años 1950, en la Playa de Agua Dulce, tuvimos la oportunidad de observar la forma amable pero distante como se saludaban los que, otrora, habían sido amigos de confianza. 


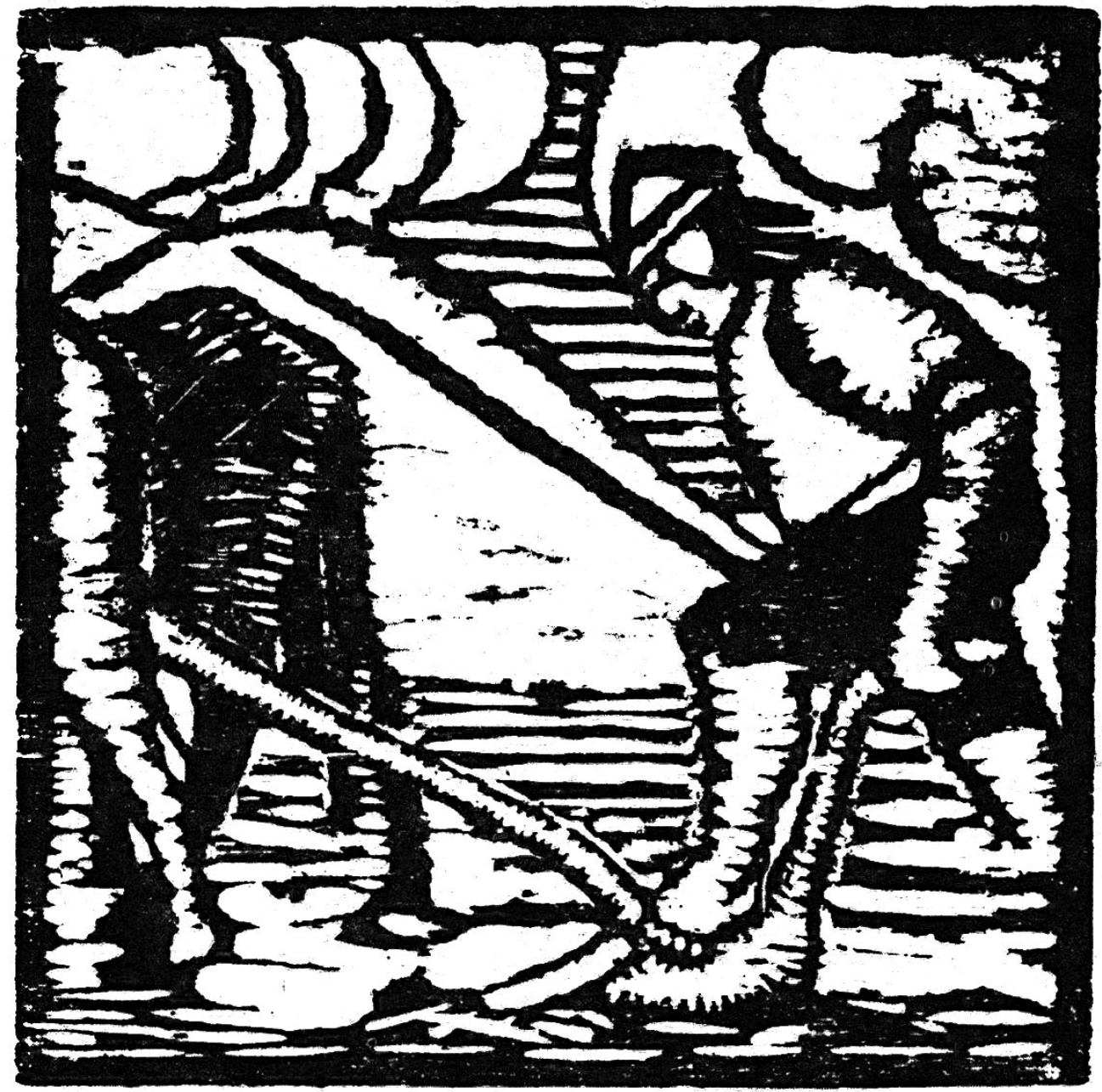

Detalle de la carátula de la Revista CUNAN No 3, por Manuel Domingo Pantigoso. 